\title{
Teaching Gender in a Transnational Perspective - Challenges, Resistances and Strategies
}

\section{By Connie Carøe Christiansen and Diana HøJlund Madsen}

\begin{abstract}
This opening article argues for the need for adopting a transnational perspective in the teaching of gender in the classroom, an approach which has considerable resemblance with Mohanty's 'Feminist solidarity or comparative feminist studies model' of teaching. The article contributes to an on-going scholarly debate on the teaching of gender in higher education by specifying how the transnational feminist perspective could be adopted in practice, both in classrooms and in cooperation between universities. Three points that this perspective gives rise to - the translations of gender, the inherent teaching strategies, and the teaching pedagogy involved - are discussed as they call for reflections on the power dynamics between researchers from the Global North and South and the representations of these poles in class-rooms. The article concludes with some more concrete suggestions for addressing, rather than silencing, the transnational dimension embedded in the practice of teaching gender.
\end{abstract}

\section{KEYWORDS}

feminist pedagogy, gender, teaching strategies, transnational feminism/ feministisk pedagogik, køn, undervisningsstrategier, transnational feminisme

Diana Højlund Madsen is Assistant Professor at the Department of Culture and Global Studies, Freia, Aalborg University, Denmark. Her main research areas are gender and development and gender and conflict, working on research projects in Rwanda and Ghana. She teaches at Development and International Relations (DIR) - mainly at the specialisations Global Gender Studies (GGS) and Global Refugee Studies (GRS).

Connie Carøe Christiansen is Senior Advisor at KVINFO, the Danish Centre for Equality, Gender and Diversity in Copenhagen, Denmark. She has researched, taught and published in the field of gender, migration, Islam and development and is part of a project to establish a Master Programme in Gender and Development at the Gender-Development Research and Studies Centre at Sana'a University in Yemen. 


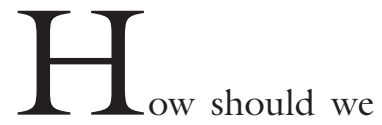
teach gender in higher education? Is there a feminist pedagogy? How does one's own positioning combine constructively and critically with teaching gender? The discussion of how the feminist project should be reflected in gender studies is not new (Spivak 1993; Coffey \& Delamont 2000; Moya 2006; Tolan \& Ferrebe 2012; Orr et al. 2012), but in this opening article we seek to take the discussion one step further by focusing specifically on the cross-border nature of feminist inquiry and the trans-locality of feminism as scholarly work and as a project of social change - in the class room. We argue that it is imperative for the pedagogy of gender studies to reflect historical and present-time inter-cultural connections. Gender studies can no longer - or in fact never could - be safely studied within specific boundaries, geographically, culturally, or socially (Mohanty 2003). At least if the questioning of 'the malestream of knowledge, the taken-for-granted' (Coffey \& Delamont 2000: 1) lies at the heart of the feminist project. Besides, universities have increasingly 'internationalised' their study programmes and attract students from around the globe. In our discussion we draw on postcolonial scholarly work, on the teachers of gender studies of this volume who have shared their experiences and reflections on their own teaching, and we draw on our own practical experiences of teaching gender at Danish Universities and in a Danish-Arab partnership project.

The curricula of gender studies are being internationalized (Parisi 2012; Mohanty 2003), but the increasing interaction within, and migration for, higher education on transnational, regional and global scales have not presented gender studies with a new set of methodological challenges; they were there already. Instead, it is currently necessary to give new impetus to the discussion of the pedagogy applied in gender studies using lived and experienced examples. The core question here is: How do we connect different cross-regional social contexts in practical teaching, when we study power relations as gendered? Usually we find that they not only differ from one context to another, but also that they should be supplemented with other equally powerladen dimensions of analysis. This issue is complicated by the impossibility of not already being positioned; in terms of feminism, in terms of teaching, in terms of the history of women's movements, in terms of multi-ethnicities and migration. We are as teachers, and not only as researchers, already embedded in 'the particular' (Abu-Lughod 1991).

In the following we first discuss how the scholarly debate of feminist positioning and women's movements in a globalizing world has unfolded - in a movement from a universalizing 'global' to a more refined 'transnational' perspective where specific localities are highlighted but not privileged. Second, we point out how this perspective has consequences for teaching gender; and finally, we draw on our own teaching experiences for reaching the contours of a feminist pedagogy in which such an understanding of the transnational perspective is prominent, and we highlight some possible aspects of such pedagogy and their implications in the classroom. We end with some concluding comments on how the transnational dimension can be addressed in teaching.

\section{FROM GLOBAL TO}

\section{TRANSNATIONAL FEMINISM}

Based on the general observation that a national framework for feminism is not tenable in a globalizing world, new forms of collective action and solidarity among feminist movements are evident and increasingly take on a global or supra-national perspecti- 
ve. Often, they are indiscriminately referred to as transnational feminism (Mendoza 2002; Moghadam 2005; Ferree \& Tripp 2005; Lim 2015).

Thus, the common goal for women, based on assumptions of a common patriarchy reigning globally, is for scholars such as Moghadam (2005) not an assumption of the past; instead a slogan originating in the 1980s, "Sisterhood is Global", is pushed for-ward with new vigour (ibid.). In contrast, Mendoza (lecture at Roskilde University June lst 2010) finds that the question continues to be on what basis a cross-cultural solidarity can be formulated, since 'global sisterhood' cannot be taken for granted. From the vantage point of today, Mendoza claims it possible to re-evaluate the high hopes connected to transnational feminist networks:

Transnational feminism after all these years has still not offered us an answer to the question of what constitutes the common ground of feminist transnational solidarity and how it can translate in political terms" (Mendoza 2010).

In Mendoza's estimate it is highly uncertain that current feminist transnational networks are more promising in terms of practicing solidarity between women. Moghadam, on the other hand, finds that such evidence is available in the feminism which came into existence during the 1980s in the shape of transnational feminist networks, gaining momentum in the aftermath of UN World conferences in 1985 and 1995 (Moghadam 2005: 90). Such transnational networks of feminist organizations emerged as a result of rapprochement between Third World feminists and feminists of the North, and a mutual recognition of the issues that each side gives priority to, turning body politics and economic conditions into common issues, rather than, as previously, issues that separate them. Moghadam finds that most Transnational Fe- minist Networks (TFN) have a broad political framework. However, one TFN has a narrower objective since it was established by an Afghan expatriate in the US. This organization, called Women's Alliance for Peace and Human Rights in Afghanistan, and its success in preventing the US government from acknowledging the Taleban government, is in Moghadam's view due to the fact that the organization lobbied along with US based feminist organizations and managed to influence the government. In other words, this kind of lobbyism connecting two feminist organizations localized on different continents and in different national contexts is to Moghadam evidence that transnational feminism is now truly global (Ibid.: 9). Moghadam's example is, however, also a limited kind of transnational feminism, since it applies a transnational feminism in perspective but not in method (Al-Ali \& Pratt 2009). This distinction, we find, is relevant for how gender studies are practiced in the class room and below we introduce Mohanty's (2003) three models for feminist teaching to further clarify just how.

\section{IS SISTERHOOD GLOBAL?}

The global perspective was inherent in gender studies from the inception of the field. In the mid-1980s the seminal publication, Sisterhood is Global (Morgan 1984) was launched, already taking the relevance of the global for granted; it resonated well with the assumption that women's oppression was universal, ubiquitous - global. The global dimension of teaching gender may thus seem not only a highly relevant preoccupation in a global age which is said to be ours, but today it may also seem a quite banal observation, since the global as a perspective or process already went mainstream in university curricula decades ago; as Parisi (2012) points out, this happened with the internationalisation of universities which again went in tandem with the de- 
velopment of neoliberal universities (Jurkinen \& Penttinen, this volume). However, as Parisi (2012) also observes, another article - Mohanty's earlier seminal publication Under Western Eyes: Feminist Scholarship and Colonial Discourses (Mohanty 1984) - confirmed that two parallel trajectories of gender studies existed, and Mohanty's criticism of the universalization of white feminism sparked a scholarly debate on differences in experiences and realities amongst women (Nicholson 1990; Haraway 1988; Hawkesworth 1989).

A radical questioning of the way we construct knowledge continues to be a main task for a feminist pedagogy, and in our view 'inequality' perhaps more than 'difference' is an underlying premise of feminist activity and teaching. Mohanty thus reminds us that one needs to reflect on the underlying assumptions on gender and ethnicity / race and the "politics of knowledge at work" when developing a curriculum (Mohanty 2003: 518) - both in the overall framework within which the curriculum is developed and in the specific content of the curriculum. Mohanty suggests that three pedagogical models are in existence (Ibid.: 518 - 524), while also rejecting the first two: the 'Feminist-as-tourist model' and the 'Feminist-as-explorer model'. The 'Feminist-as-tourist model' has a main focus on Western perspectives and examples from non-Western contexts are brought in to add to this perspective. Mohanty labels this the 'white women's burden' perspective. The 'Feminist-as-explorer model' mainly focuses on 'foreign' women and men and this perspective allows to explore in-depth the everyday lives of these women and men. In both of these models the curriculum of gender studies reproduces the often critizised centre-periphery and us-them constructions in their narratives of gender, power and difference, even if they, especially in the second model, include gender perspectives from nonwhite, non-Western or Global South con- texts. In contrast, the third model, called the 'Feminist solidarity or comparative feminist studies model', creates inter-linkages between 'the local' and 'the global' to demonstrate how they mutually constitute each other:

"This framework assumes a comparative focus and analysis of the directionality of power no matter what the subject of the women's studies course is - and it assumes both distance and proximity (specific / universal) as its analytical strategy" (Mohanty 2003: 521).

In other words, selecting a substantive gender issue and highlighting it from the "history, experience and struggles" (Mohanty 2002: 522) of different women worldwide (European, immigrant, Third World) to form the basis for solidarity between women from different contexts is the pedagogical model preferred by Mohanty.

Needless to say, this position is contested; no consensus which may form the basis of an 'internationalisation' of the curricula of gender studies is in existence. Although the supra-national character of feminism is not a recent observation, inspired by Mohanty's comparative feminist model and by recent transnational feminist studies, we may say that there is a need to move the curriculum of gender studies more firmly into a transnational framework for teaching.

\section{The Global / Transnational IN THE TEACHING OF GENDER}

To clarify, we therefore suggest that in a transnational feminist perspective the way that gender is localised and contextualized, or assume specific features of inequality as a consequence of global and local power structures, take centre stage (see, e.g., Lim 2015). The ability of feminism to travel across political and social boundaries involves questions about cross-cultural connectedness, inequality, and power asymmetries, 
also among women. Consequently, transnational feminism should be understood as the connecting of feminist agendas in different contexts in order to trace how gendered hierarchies intersect with post-colonial structures of race, culture or 'ethnicity', and thus to not assume that these hierarchies collapse into one (Tambe 2005; Salih 2005; Al-Ali \& Pratt 2009). This is how feminist transnationalism constitutes a method or an approach and goes beyond signifying an extension of feminist networks or movements beyond national borders (Al-Ali \& Pratt 2009).

At least three issues lend themselves to closer scrutiny when teaching gender is highlighted as a transnational practice. One of them is that the meaning of gender as a term appears to be multiple, and not universal, thus it requires not only understanding but also translation. Another is how 'the transnational' as a dimension figures in teaching strategies, a question which involves the issue of how gender studies (con)figures in neoliberal institutional settings, and how transnational gender cooperation could take place. A third issue is what a transnational feminist pedagogy might mean.

\section{GENDER READINGS-TransLations}

If local meanings of gender is taken into account in teaching practices, and not just dismissed as faulty interpretations of a universal term, how does it inform teaching? An agenda of reading-translating gender may in combination with learning objectives constitute a difficult paradox or at least a huge task for the individual teacher. If by the term 'gender', researchers want to establish a fairly delimited and meaningful, although contested, analytical term, it is often presented as primarily a matter of pedagogical skills of teachers and receptiveness amongst students, and several of the articles in this volume take this position, while revealing the pedagogical tools applied, and discussing the effect on students' learning process. It may also be argued that the 'gender' in gender studies have at this point reached a relatively shared set of meanings which are taught in Brazil (Pinto), in Finland (Jyrkinen \& Penttinen) and in Denmark (Horn) alike, even if the context in which the teaching occurs needs to be taken into account.

Relevant for the transnational perspective on teaching gender is however the fact that the concept of gender seems to possess a rich potential for creating multiple meanings and understandings, perhaps due to the difficulty of translating 'gender' smoothly into other languages. Its introduction to some countries has been accompanied by the idea that gender is a Western construct. Thus, Abirafeh (2010) points to the specific understanding of 'gender' found among Afghans in their reception of the term in the early 2000s, a highly politicized moment in Afghanistan's transnational relations due to the 'war on terror'. It is Abirafeh's observation of the aid industry growing from interventions by US and allies that often no attempt was made to translate gender to the local Pashtun language, but the salience of referring to gender for international donors and the aid community did not escape the Afghans. According to Abirafeh: "Gender is a buzzword in contemporary aid discourse that peppers aid reports, policies, and program plans" (Abirafeh 2009: 50). For the Afghans applying for donor support or watching their wives leave the house to take part in a 'gender project', gender referred to the real focus of the projects, namely the promotion of women, usually perceived as being at the expense of men.

Now, the Afghan case is clearly a case which brings out extrem because of the war context, but it may spell out the lesson to be learned with all the more clarity. Afghans are not alone in presenting alternative versions of what gender might mean. Just like many other languages, Arabic does 
not have a term that smoothly translates gender (Mehrez 2007), and attempts to translate the concept may become entangled in political struggles as a consequence of popular and media-transmitted representations. The understandings which emerge - just like in Abirafeh's account of the Afghan case - may not correspond to the understandings found in any text in the curricula of gender studies. Consequently, they may be apprehended as 'misunderstandings' or as 'demonizing discourses' found in the popular press and in the street (Badran 2009: 193). For example in Yemen during the mid-1990s, it became possible for politicians from Islamic parties to articulate the Women's Empirical Studies and Training Center at Sana'a University as a place of variously pornographic and lesbian activities, partly due to the associations that 'gender' install in translations to Arabic, and the Center was finally closed down when a Moroccan researcher questioned the current chronology of Quranic verses at a conference organized by the center and transmitted on national television (Willemson \& Van Lening 2002; Badran 2009). In addi-tion, in the teaching of Yemeni master students during the years 2011-2016, students repeatedly referred to 'women' and disregarded standard academic definitions of gender. The concept of gender has already been introduced by development agencies which tend to spell out the meaning of gender by calling development projects 'gender-sensitive' or 'gender-mainstreamed', in spite of most of them only targeting women.

In a transnational feminist pedagogic approach this understanding is not disregarded as a misapprehension or a 'faulty' understanding of the term. In a Ghanaian setting, Manuh (2007) puts forward that although gender may not be easily translated into the local languages, it is a relative recent concept and it is also a somewhat western concept which should not prevent the Ghanaian researchers and activists from using it. The lack of a local language has not prevented the use of other concepts:

What has mattered is that using gender as a badge and compass, activist women and a few men have attempted to deal with a multiplicity of issues facing women and men in society and the economy in ways that seem to have the potential to transform society and politics (Manuh 2007: 131).

Thus, Manuh argues that the usefulness of the concept of 'gender' should be measured by its usefulness for gender activists and researchers in order to overcome this resistance. In addition, the number of persons (often women) involved in activism and research frequently overlap as they are not seen as separate but rather linked activities.

Neither is using 'gender' as a marker for a range of issues, rather than as an anytical term, to endorse text book meanings. These examples of (class room) practices can be approached as interpretations of not only a concept but also of contexts presenting frames of understanding for that concept; and these understandings tell us that 'gender' needs to be approached from the postcolonial reader's position, excluding the monolingual and favoring the position as "'in between', at once capable of reading and translating" (Mehrez 2007: 107). This seems a favorable position for teachers in gender studies programmes, probably every-where and not just in countries of the global South, as demonstrated by the pedagogical experimenting that the authors of this volume have been conducting in order to only just reach a receptive student audience. The position as 'outside in the teaching machine' (Spivak 1993) of gender studies is perhaps most of all evident in this maneuvering.

\section{TeAching STrategies From A Transnational Perspective}

In the context of Aalborg University tea- 
ching, gender has recently (from 2014) undergone some positive changes as a specialisation in Global Gender Studies as a part of the Master programme on Gender and International Relations. Although this specialization has in some cases replaced specific lectures on gender in some courses, they continue in other courses, for example International Relations where the whole group of students in the Master programmes is required to participate - a strategy of both mainstreaming gender and keeping a specific focus on it. This has somewhat changed the perspective on gender to become more broadly accepted instead of being associated (only) with 'alternative'/'new' theories or as Horn (this volume) writes, 'critical theories'.

In our teaching at Global Gender Studies, we have tried to adopt aspects from the 'Feminist solidarity or comparative feminist studies model' by bringing forward perspectives from both a European and Global South context. The notion of 'development' relates to a number of theories on processes of economic, political and social development in the developing world. However, processes of development are of a global nature and relate to the developed world through colonialism, development aid, global gender norms, et cetera, and as such close inter-linkages exist between the First and the Third world, between the Global North and South. For example, one of the authors has been teaching on the gendered and racialized representations in publications from a development agency where the students were divided into groups and asked to reflect on these representations and the potential implications for development policy and practice. In the debate it emerged that men are represented as lazy, irresponsible and controlling in cartoons and women in contrast as hard working, entrepreneurs and on their way to becoming liberated. However, as a result of looking into how the 'other' men and women are represented, the students also star- ted to ask and debate gender equality in the Danish context. It was important to include men as well as women to signal that gender is about both and that they are mutually constructed. In addition, the debate touched upon the construction of 'Western' men and women as being the opposite of the 'other' - namely gender equal.

Mohanty presents a narrative view on gender curricula by reminding us that: "After all, the way we construct our curricula and the pedagogies we use to put such curricula into practice tell a story - or tell many stories" (Mohanty 2003: 517). Thereby Mohanty also stresses the importance of reflecting on what stories we choose to tell when we develop a curriculum - there are gendered and racialized implications. However, we would argue that the 'Feminist solidarity or comparative feminist studies model', in the version presented by Mohanty, has a couple of weaknesses. First, she does not include a focus on men and masculinities and thereby indirectly contributes to a reinforcement of the argument that gender and feminism is related to women (only) e.g. the notion of 'hegemonic masculinity' (Connell \& Messerschmidt 2005) could be explored further in different contexts. Second, her model is quite ambitious and challenging for the teacher which also has repercussions for the transnational feminist approach. The teacher should, for example, be aware of gender issues within a European context as well as of those gender issues and conceptualizations that immigrant women and men to Europe and women and men in the Global South live by. Many gender researchers are specialised within their area, e.g. development and gender, ethnic/race studies or gender and Danish/ Nordic/European gender studies - fewer teachers may be able to actually connect from one part of the world to another, or from one scale to another, and in each case bring the 'politics of knowledge' in view, as envisaged by Mohanty. Such shortcomings 
will effectively exclude gender translations from the class room.

\section{Transnational Gender COOPERATION}

The focus on solidarity should not be isolated to principles for the curriculum, it should also include strategies for expanding the agenda of practicing it in collaborations among universities. One of these strategies would be to build "strategic cross-campus alliances" (Parisi 2012: 318) which would serve to ensure the spread of gender programmes to other parts of the campus. Another strategy could be not just to educate the students to jobs within the professional 'Gender-and-Development' context but also raise their awareness about global solidarity movements with a focus on gender. Jad (2009) warns about the NGOization and professionalization of such solidarity movements; universities should make sure that these critical global perspectives are adopted and not just "tick off the global citizenship box on its checklist" (Parisi 2012: 319) - one needs to ensure that the students are equipped to question existing notions of, for example, global sisterhood. Yet another strategy is the possibility of setting up international programmes with external funding between different gender centres, gender research groups and gender programmes between the North and South as a possibility for exchange (Parisi 2012: 320).

For one the authors of this article, as a coordinator and teacher in a collaborative project between Roskilde University (RUC) and the Gender-Development Research and Studies Centre (GDRSC), Sana'a University in Yemen, gender cooperation was brought to the fore, along with an opportunity to experience the transnational interconnectedness of gender issues, and the acuteness of gender translations. The project has developed a Master programme in International Development and Gender
(MIDG), which is supported by DANIDA as a part of the Danish-Arab Partnership Programme, with a budget for the Yemeni and the Danish partners respectively. For the Yemeni partners it was important that the embeddedness of the course in Yemeni society and in the Middle Eastern region was apparent in the course literature and in contacts established to gender and development research and education centers elsewhere in the region. The first batch of students was enrolled during January 2011 , after public announcements in the Yemeni media.

Teaching gender and development to these students was a challenge along lines otherwise unknown to a Danish framework. In accordance with the wish expressed by the Yemeni partners, the Roskilde curriculum in international development studies was adopted for the MIDG with adjustments considering the main objectives of the programme as placed in Yemen and taking the local context into consideration. This involved adding the 'gender' dimension, also in the title. Thus, the formulation of the title of the programme took into consideration the pre-history of the project (i.e. the closing down of the previous gender studies centre for being too overt in its feminist stance vis-a-vis the Yemeni public) which was already reflected in the re-naming of the centre. The new master programme was therefore called: 'Master in International Development and Gender' which was a downplaying of the gender component. The argument for this was twofold: It was regarded as a strategy to avoid associations with the scandal and closure of the former centre and as a strategy to open up the programme for students who primarily needed a master in International Development Studies, but would accept a gender component.

The readings for the course are currently 'mainstream' textbooks of international development studies and articles and book extracts which ensures that a Middle Eastern, 
a Yemeni and/or a gender perspective is included in the lecture. Throughout the programme, students are offered courses that have gender as an integrated or central element. Co-teaching was introduced by GDRSC to the RUC collaborators as an essential element of the partnership, consisting of one 'international' or partner teacher from RUC planning the course and to some extent teaching in co-operation with one teacher from GDRSC - a two-way capacity learning in practice. With a few exceptions, the project has been characterized by, squarely put, a schism between teachers from Sana'a University who have the competencies to teach but not the enthusiasm for gender studies, and those who do not possess the competencies to teach but share the enthusiasm. This schism is currently being overcome by recruiting new teachers from outside the university and by teachers attached to the centre becoming more skilled in teaching international development and gender. During co-teaching of two batches of students, it became clear that the approach to the course readings of the Yemeni students inherently assumed the purpose of readings to be accumulating background knowledge, rather than to engage with the texts in direct dialogue. At least the first teaching sessions made clear that learning style is a topic that needs to be addressed squarely in the process of teaching, both by teachers and students.

In development projects, the labeling of the collaboration as a 'partnership' often serves more to support the silencing of the power relations than to secure that the collaboration is equal in terms of influence and responsibilities. 'Partnership', as Cornwall and Brock point out, is a buzzword which may blur the actual relationships of power at work in projects:

Particular combinations of buzzwords are linked together in development policies through what Laclau (1996) calls "chains of equivalence": words that work together to evoke a particular set of meanings (Cornwall \& Brock 2005:12).

The specific works of power or the Pword' (Eyben 2005: 5 ) in the partnership, although evidently effective, is often avoided as 'the elephant in the room'. According to Vandermoortele, essentially partnerships take two forms, either the form of 'money changing hands' or of 'ideas changing minds' (Cornwall \& Brock 2005). In the project aiming to develop a Master programme, the exchange of money is supplemented by the exchange of ideas. The teachers involved from Sana'a University had no experience in teaching international development and the transfer of teaching skills in international development studies from Roskilde University to GDRSC has an in-built exchange which on the other hand encouraged RUC teachers to reflect on the way that 'gender work' in Yemen is unfolded in the development sector already employing many of the students. For the RUC teachers, teaching the programme in Yemen was a seldom opportunity to teach students already working in the field of stu$\mathrm{dy}$, and to be confronted with the 'gender workers', since some of the development agents in fact interpret and implement the imperative of being attentive to the gender dimension in development. The challenge for RUC teachers (including the author) was exactly to 'read' these practices of students and simultaneously to challenge them, in order to create, in the space of the class room, some kind of common narrative about what gender might mean in a Yemeni context.

\section{A Feminist Pedagogy}

Already, then, the question of whether we can talk about a 'feminist pedagogy' is necessarily a contested one, nonetheless important to discuss; should gender studies challenge the status quo of gendered power relations? If so, what would it contain? 
How do we include 'the global' in the teaching of gender? And how do we avoid overdetermining the global scale?

This issue of Women, Gender \& Research discusses concrete teaching practices and strategies in the class room for gender studies, linking them to the feminist project on different scales. Shying away from using the term 'feminism' about teaching sessions altogether may be one way to avoid negative connotations and attract students to the course (Henriksen, this volume). In their article, Pentittinen and Jyrkinen explicitly refer to 'feminist pedagogy' as characterised by "...low hierarchy in the classroom setting, sensitivity to diversity among students and the idea of learning as transformation and personal growth", not unlike Welsh who in identifying a post-colonial teaching strategy see it as "a non-hierarchical and supportive learning community that student-centered, self-reflexive learning strategies and carefully structured work-shopping activities can engender' (Welsh 2012: 153). They also describe 'feminist pedagogy' as running counter to the expectations of students as it clashes with their culture of individualism, their personal motivation to learn about their own gender versus broader social perspectives and their gendered expectations towards the look of the teachers versus their actual appearance. In their contribution they also relate how they have dealt with these challenges in their teaching.

Other articles (Haaland \& Wallevik; Horn; Pinto) also discuss aspects of 'feminist pedagogy' in their own teaching practises. Haaland \& Wallevik use experience notes in their teaching to make the students more aware about the "gendered situations for them to reflect further on how gender is constructed" and, on the basis of this, to "more critically interact with dominant generalised theories". The use of the students' experiences seems to be a common characteristic for most of the authorscum-teachers. Horn, for example, describes how she began her teaching by asking the students to introduce themselves and comment on any previous engagement with gender and later used this information during the teaching, relating to student experiences with activism. Horn also used herself to make a point, when she deliberately wore H\&M clothing manufactured from an export processing zone for a session on the global political economy. Pinto refers to how she allows emotion into her classroom and uses the method of 'empathetic cooperation' to deal with the 'inner tumult' which a focus on gender - as well as the interlinked destabilisation of other categories such as race, ethnicity, class, et cetera - creates and as a method to link with the students' experiences, as it is often difficult for them to identify the relevance of gender.

A number of the authors also mention that they teach a very diverse student group which is something they try to take into account and turn into an advantage. Horn emphasises the need to establish an inclusive learning environment and describes how students with an American Hispanic and Indian background make important contributions by bringing up other categories such as race, ethnicity and class in the discussions. Haaland and Wallevik also show how the diverse student group in their on-line course was able to reflect on their lived (gendered) experiences in their meeting with another cultural context and norms / ideas about gender. A similar experience is put forward in Stoltz (2013) as she relates how the different perspectives of her students from other places of the world provided opportunities to bring in new perspectives across borders on racism and democracy. In teaching at Aalborg University one of the theme editors experienced how a session on women's political representation and quotas with examples from different parts of the world proved an issue which lead to a lively debate. Following group work, one of the female students from China started to explain her point of 
view on the conditions of women in China, the barriers for women's participation in the political life and the structure of the political system. Through this, she made it possible to explore in depth the differences and similarities amongst the different countries. It was of importance for the exercise that Denmark was a case country too in order to localise 'status quo' in this context and question Denmark's status as one of the very gender equal Nordic countries. This would not have been possible without the representation of different perspectives and identities in the teaching situation.

What might then be the contours of a feminist pedagogy which is transnational in outlook and method, and therefore integrates reading-translating gender? In place of a lofty conclusion, we present a number of elements required for a feminist pedagogy which is reflective about its ambiguous position in the 'the teaching machine' and its inherent cross-cultural challenges. Inspired by Moya (2006: 108-114), and in line with the thinking of Mohanty, the following strategies for engaging and including students with diverse backgrounds can be identified:

- Try to make use of audio visuals as many students can relate to these. They can for example be used to illustrate examples and to stress specific points and also help create variation in the lecture.

- Get to know the students as a diverse group. You can obtain lists of the students in class beforehand and/or ask your colleagues about the student group.

- Aim to get the students' perspectives; potentially using 'buzzing groups', small exercises with post-its, or 'small-scale surveys' on the students' knowledge, experiences, points of view or understandings of the concepts used in class (e.g. gender and ethnicity/race).

- Use group work if the time allows - potentially the groups could be organised with students of similar or different gender and ethnicity/race categorisations, depending on the purpose. Group work forms a basis for including students' experiences and perspectives but also a basis for the students to get to know each other. In addition, group work is potentially less frightening for shy students and could therefore facilitate a more inclusive learning environment.

- Bring in examples from different cultural contexts in the teaching, and point out their connections, currently and historically or by bringing in a 'flow'-perspective, e.g. with a focus on people, capital and goods. This will make it easier for the students to relate to diversity and acknowledge it.

- Be present during breaks as a lot of questions may be posed exactly at this point especially from students who are too shy to speak in larger groups (in many cases female students). The questions posed can often be used as an input for the lecture after the break. Also, interested students may want to ask about further references for literature, resource persons, et cetera.

- Bring your own background into the lecture - not only the students have gendered and racialised perspectives and experiences. If the students' perspectives are brought in it would be natural to bring forward the perspective of the teacher. However, make it clear from which position you talk.

- Try to identify the students' expectations towards you as a teacher as this may influence their outcome of the lecture. As a relative young, white and female teacher the students may perceive you as a 'missionary' trying to persuade them to 'buy into' the (arguments for the) importance of gender. They may also perceive you as a 'gender expert' in the sense of a consultant, as especially some of the international students from developing countries have often met relatively young, white females in this role in relation to gender projects or programmes. - Pay attention to bringing forward minority issues and issues on discrimination in the teaching environment - be aware of the 
(im)balances present in class as they may need to be addressed/supported.

- Link the lecture to the students' everyday lives and context if in any way possible. In that way they will have a better chance of grasping it by relating to well-known aspects.

\section{CONCLUDING COMMENTS}

The opening article has offered reflections and ideas for inspiration on how to teach applying a transnational feminist perspective and thereby approaching Mohanty's 'Feminist solidarity or comparative feminist studies model'. Drawing on our own experiences and other articles in this special issue, we have argued that in order to practice a transnational feminist pedagogy, gendered and racialized perspectives are inherent in the content and pedagogy of teaching, not as a consequence of a diverse student group, but as a consequence of transformative knowledge-claims. We have also argued that in practicing a transnational feminist pedagogy we need to facilitate transnational collaboration with other researchers and universities, although this may not be an uncomplicated exercise. Above all, the article pinpoints that the power dynamics of gender embedded in transnational North-South collaboration need to be addressed - both in- and outside the classroom, although it may be impossible or at least difficult as an individual researcher to erase them.

\section{Note}

1. This article has been reviewed internally by the main editorial board of Women, Gender \& Society

\section{REFERENCES}

- Abirafeh, Lina (2009): Gender and International Aid in Afghanistan. Jefferson: Mcfarland and Inc. Publishers.

- Abu-Lughod, Lila (1991): Writing Against Culture, in: Fox, R. (ed.): Recapturing Anthropology. Working in the Present. School of American Research Press, Santa Fe: 137- 162.

- Al-Ali, Nadje \& Pratt, Nicola (eds.) (2009):

Women and War in the Middle East. Transnational Perspectives. Zed Books, London.

- Badran, Margot (2009): Feminism in Islam. Secular and Religious Convergences. Oneworld Publications, Oxford.

- Coffey, Amanda \& Delamont, Sara (2000): Feminism and the classroom teacher. Research, Praxis, Pedagogy. Routledge, London.

. Connell, R. W. \& Messerschmidt, J. (2005): Hegemonic masculinity - Rethinking the Concept, in: Gender o Society 2005/19/6

. Cornwall, Andrea (2007): Revisiting the 'Gender Agenda', in: IDS Bulletin 2007/38/2: 69-78.

. Cornwall, Andrea \& Brock, Karen: Beyond buzzwords. "Poverty Reduction", "Participation" and "Empowerment" in Development Policy. Overarching Concerns, in: Programme Paper no. 10 . UNRISD:http://www.unrisd.org/80256B3C005 BCCF9/(httpAuxPages)/F25D3D6D27E2AlAC C12570CB002FFA9A/\$file/cornwall.pdf

- Eyben, Rosalind (2005): Relationships for Aid. Earthscan, London.

- Ferree, Myra Marx \& Aili, Mari Tripp (eds.) (2005): Transnational Women's Activism, Organizing and Human Rights. New York University Press, New York.

- Gairula, Rahul K. (2012): Occupy Education. An interview with Gayatri Chakravorty Spivak. Located at: http://politicsandculture.org/2012/ 09/25/occupy-education-an-interview-with-gayatri-chakravorty-spivak/

- Haraway, Donna (1988): Situated Knowledges: The Science Question in Feminism and the Privilege of Partial Perspectives, in: Feminist Studies 1988/14/3: 575-599.

. Hawkesworth, Mary K. (1989): Knowers, knowing, known; Feminist theory and claims of truth, in: Signs: Journal of Women in Culture and Society 1989/14/3: 533-557.

- Jad, Islah (2004): The NGOisation of Arab Women's Movement, in: IDS Bulletin, 2004/35/4: 34-42.

- Lim, Adelyn (2015): Transnational Feminism and Women's Movement in Post-1997 Hong Kong. Solidarity Beyond the State. Hong Kong University Press, Hong Kong. 
- Manuh, Takyiwaa (2007): Doing Gender Work in Ghana, in: Cole, Catherine M.; · Manuh, Takyiwaa \& Miescher, Stephan F. (eds.): Africa After Gender? Indiana University Press.

- Mehrez, Samia (2007): Translating Gender, in: Journal of Middle East Women's Studies 2007/3/1: 106-127.

- Mendoza, Breny (2002): Transnational Feminisms in Question, in: Feminist Theory 2002/3/3: 313-332.

- Mendoza, Breny (2010): The Challenges of Transnational Feminisms in the New Age of Genocide. Guest Lecture, June 1st, Centre for Gender, Power and Diversity, Roskilde University.

- Moghadam, Valentine M. (2005): Globalizing Women. Transnational Feminist Networks. The John Hopkins University Press, Baltimore.

- Mohanty, Chandra T. (1984): Under Western

Eyes: Feminist Scholarship and Colonial Discourses, in: Boundary 2 1984/12:3-13:1, 333-358.

- Mohanty, Chandra Talpade (2003): “Under

Western Eyes" Revisited: Feminist Solidarity through Anti-Capitalist Struggles, in: Signs: Journal of Women in Culture and Society 2003/28/2: 499-

535 .

- Morgan, Robin (1984): Sisterhood is Global. The International Women's Movement Anthology. The Feminist Press at the City University of New York, New York.

- Moya, Paula M. L. (2006): What's Identity Got to Do With It? Mobilizing Identities in the Multicultural Classroom, in: Alcoff, Linda Martín et al. (eds.): Identity Politics Reconsidered. Palgrave Macmillan, New York.
- Nicholson, Linda J. (ed.) (1990): Feminism/ Postmodernism. Routledge, London.

- Richter-Devroe, Sophie (2009): "Here it is not about conflict-resolution: We can only resist": Palestinean Women's Activism in Conflict resolution and Non-violent Resistance, in: Al-Ali, Nadje \& Pratt, Nicola (eds.): Women and War in the Middle East. Transnational Perspectives. Zed Books, London.

- Parisi, Laura (2012): Transnational, in: Orr, Catherine M. et al. (eds.): Rethinking Women's and Gender Studies. Routledge, London.

- Salih, Ruba (2003): Gender in Transnationalism. Home, Longing and Belonging among Moroccan

Migrant Women. Routledge, London.

- Spivak, Gayatri C. (1993): Outside in the Teaching Machine. Routledge, New York.

· Stoltz, Pauline (2013): Gränserna för gränslös undervisning, in Hartsmar, Nanny \& Persson, Bodil Lilje (eds.): Medborgerlig bildning - Demokrati og inkludering för ett hällbart sambälle". Studenterlitteratur.

- Tambe, Ashwini (2005): The exclusive ingénue: A transnational feminist analysis of European prostitution in colonial Bombay, in: Gender \& Society 2005/19/2: 160-179.

- Welsh, Sarah Lawson (2012): Bodies, Texts, and Theories: Teaching Gender within Postcolonial Studies, in Tolan, F. \& Ferrebe, A. (eds.): Teaching Gender. Palgrave Macmillan, New York. - Willemsen, Tineke \& Van Lenning, Alkeline (2002): Women's Studies Project in Yemen: Experience from the counterpoint's viewpoints, in: The Women's International Forum, 2002/25. 